\title{
A Review of Granulation Process for Blast Furnace Slag
}

\author{
Pengfei Yu, Shuzhong Wang, Yanhui Li and Guixi Xu \\ Key Laboratory of Thermo-Fluid Science and Engineering, Ministry of Education, School of Energy and Power Engineering, Xi'an Jiaotong \\ University, Xi'an, Shaanxi ,710049, China
}

\begin{abstract}
Molten slags of blast furnace is a second resources with great value of 1600 1 800 MJ sensible heat per ton. At present, water-quenching process plays a leading role in recovering waste heat of the molten slags. However, this method not only cost lots of water, but also recover little sensible heat and can pollute the surrounding environment. Dry granulation process, as an environmentally friendly method with high-efficiency heat recovery, have attracted widespread attentions. In this paper, the water quenching and dry granulation processes were discussed in detail. After a thorough comparative analysis of various treatment technologies, it can be concluded that centrifugal granulation affiliated with dry granulation is the optimum process, with smaller slag particle size (about $2 \mathrm{~mm}$ ), more glassy phase and higher recovery rate.
\end{abstract}

\section{Introduction}

The steel industry is one of the most energy-intensive industries in China. Based on statistics of World Steel Association, China's crude steel output reaches 823 million tons in 2014 , accounting for $49.4 \%$ of the global proportion. In the first eight months of 2015, China's produced 543.02 Mt of crude steel [1]. Although the energy consumption get a slight decrease this year, the production condition and structure are different among different enterprises as well as the energy conservation, and the inefficient capacities account for a comparatively great proportion, which result in a certain gap of the average energy consumption in China compared with the developed countries level. Therefore there is a great energy-saving potential in China. The Blast Furnace (BF) energy consumption account for the largest percentage, and responsibly, it should bear more energy conservation and emissions reduction such as BF slag sensible heat recovery.

\section{Blast furnace slag and its utilizations}

Blast furnace slag is a by-product of blast furnace (BF) ironmaking produce. Every pig iron production is accompany by $0.3 \sim 0.6$ tons of blast furnace slag produced with the temperature of $1350{ }^{\circ} \mathrm{C} \sim 1450{ }^{\circ} \mathrm{C}$ $(1600 \sim 1800$ MJ sensible heat, equivalent to $55 \sim 61 \mathrm{~kg}$ standard coal combustion after the heat generated). On this basis, the BF slag is up to 247 million tons in 2014, corresponding to 11 million tons standard coal, approximating $14.0 \%$ of consumption in the BF process.

Generally, according to the cooling rate, blast furnace slag processing can be divided into quenching, half- quenching and slow cold. Because of their different properties, the products, which mainly consist of pelletized blast-furnace slag, expanded slag ball and dry slag, have different function.

\section{Water-Quenching process}

So far, water treatment method is widely used in the cooling method of blast furnace slag. There are many kinds of water treatment method for BF SLAG, such as Advection Sedimentation Tank, RASA, INBA, MTC, TYNA, and RASA. The method of RASA is adopted extensively in the steel plant in China as well as INBA.

\subsection{RASA}

Dehydration facilities of the RASA (Fig. 1) is composed of several filtering basins, which is made up of layers of different particle size pebble bed at the bottom. In blunt box, high pressure water from porous nozzle jet will quench the molten BF slag. In the next case, water quenching slag pours through graining tank and flows into the settling pond. After filtration, the slag is grabbed by grabbing crane and stacked in the SLAG field to further dewater. The water and suspended solids in the pond flow into the filter tank, filtered by the pebble bed. Filtered water collect and pump into the cooling tower, recycling. Water loss added by new water.

\subsection{INBA}

In the early 1980s, the method of INBA was first designed by $\mathrm{P} \& \mathrm{~W}$ of Luxembourg and SIDMAR of Belgium. Baosteel group first introduced the technology 
and many steel plants still uses this process which is shown in Fig. 2. It can be divided into hot INBA, cold INBA and environmentally friendly INBA. The greatest advantage is low sulfur emissions, which was most transported to the water-cycle system.

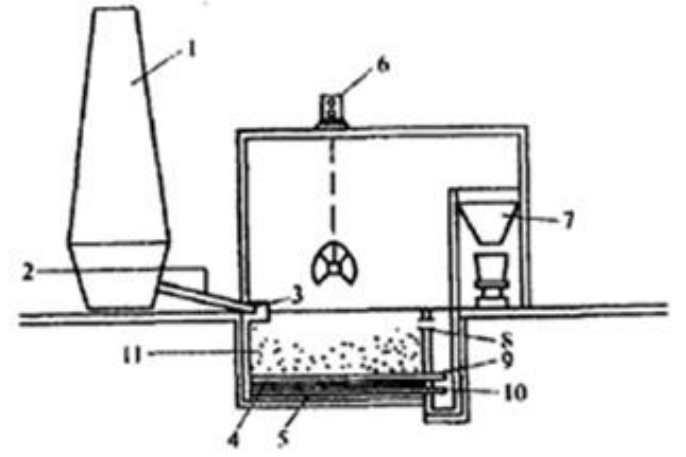

1-clinker ejector, 2-water slag ditch, 3-water slag tank, 4distributor, 5-drum filter, 6-buffer tank, 7-collecting tank, 8 - thermal basin, 9- cooling tower, 10-water tank, 11-belt conveyor, 12 -product bin

Figure 1. RASA process.

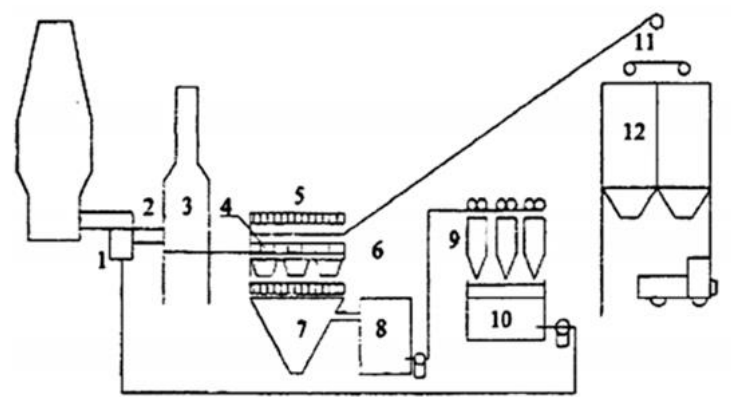

1-blast furnace, 2-clinker ejector, 3-granulator, 4-guard rail, 5-sewerage of RASA, 6- grabbing crane, 7- storage hopper, 8-overflow, 9-inlet of flushing air, 10-water outlet, 11-granulated slag

Figure 2. INBA process.

\section{Dry granulation process}

On the blast furnace slag treatment technology, for a long time, water quenching process has token the leading position. However, there are many defects of waterquenching slag method, which can be roughly concluded as follow: a mass of sensible heat unrecovered, high water consumption, air pollution, huge system maintenance workload and high power consumption. These problems greatly reduce the utilization value of $\mathrm{BF}$ slag as, which go against the energy recycling and sustainable development. As a result, it is the inevitable trend to develop an environment friendly and control reliable dry granulation process with high value-added products and high rate of waste-heat recovery.

Dry granulation is a technology of no new water consumption, direct or indirect contact with blast furnace slag to recover sensible heat. And at the same time it will use mechanical power or high pressure air to make slag granulating, without harmful gas discharge, a new type of environmentally friendly technology for slag treatment. According to the slag crushed process, many methods have been proposed. Those which have great influence are rotating drum process, air blast method and centrifugal granulate process.

\subsection{Rotating drum process}

There are two main forms of this technology: single drum and double drums.

NKK [2] built a pilot blast furnace to research the double rotating drum technology (Fig. 3) at Fukuyama. It simulates the working principle of dry quenching. Liquid slag is poured into the space between the two opposite rotating drum, and cooled by the heat transfer medium in the drum, along with the slag crushed. Recycling heat is collect to the heat recovery boiler and used to generate electricity. Although the glassy phase we can get reach about $80 \%$, the slag particle size is much bigger and must be grinded if used for cement. What's more, the slag often adheres to the drum, hard to control the thickness of slag film. As efficient organic solvents is difficult to choose, the exergy recovery is low (about 40\%). So the process has not been industrial applications.

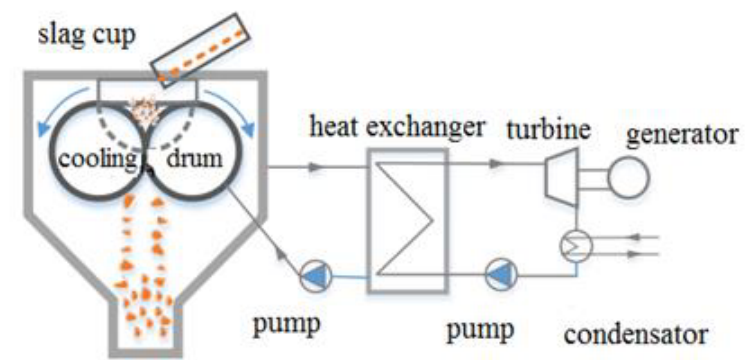

Figure 3. NKK cooling drum process.

The single rotating drum process was first put forward by Ishikawajima-Harima Heavy Industries and Sumitomo Metal [3] and the process is shown as Fig. 4. The drum with non-wetting coating on the surface rotates at a certain speed, while melted slags are poured onto the drum and thrown out, broken to particle. Meanwhile, the broken particles are gathered to fluidized bed by the falling water-quenched slag and then heat exchange with air occurred. It is reported that this process can achieve a temperature of $500^{\circ} \mathrm{C}$ heated air and slag diameter less than $10 \mathrm{~mm}$ (about 95\%). The heat recovery rate can be as high as $60 \%$. However, this method belongs to halfquenching treatment and the product mainly used for the concrete aggregate, low added-value. And the processing capacity is insufficient, hard to industrialize.

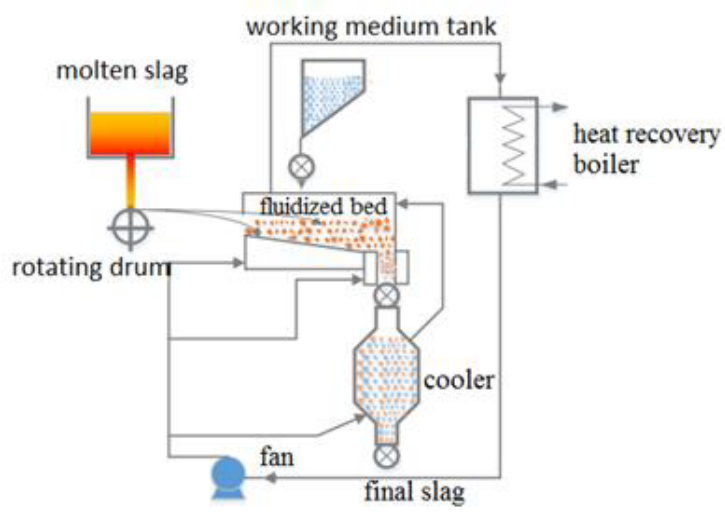

Figure 4. Sumitomo metal single rotating drum process. 


\subsection{Air blast method}

High speed and high pressure air plays a pivotal role to discharge the molten slag with a rapid cooling in this process, along with absorbing the sensible heat [4]. And then recycle heat are sent to heat recovery boiler to produce steam for power generation. Japan, Germany, Russia, etc. have studied on this technology, among which Japan have outstanding performance with industrial application. Since 1982, six major Japanese steel companies develop this process and successively carried on the experiment, half of industrialization and mass production with slag handing capacity of $40 \mathrm{t} / \mathrm{h}$ and heat recovery rate of $60 \%$. The technological process is shown in Fig. 5. Liquid slag from tilting slag ditch poured into the wind hole, granulates under the action of the air from the bottom pelletizer fan. Particles solidify during its flight, the temperature depressing from $1500{ }^{\circ} \mathrm{C}$ to $1100^{\circ} \mathrm{C}$, and then in the heat exchanger further cooled to about $300^{\circ} \mathrm{C}$. The finished slag particles less than $5 \mathrm{~mm}$ account for $95 \%$, whose glassy phase is more than 95 , similar to that of water treatment slag. And the heat recovery rate is approximate $60 \%$. However, there is no follow-up report due to its drawbacks, mainly summary as follow:

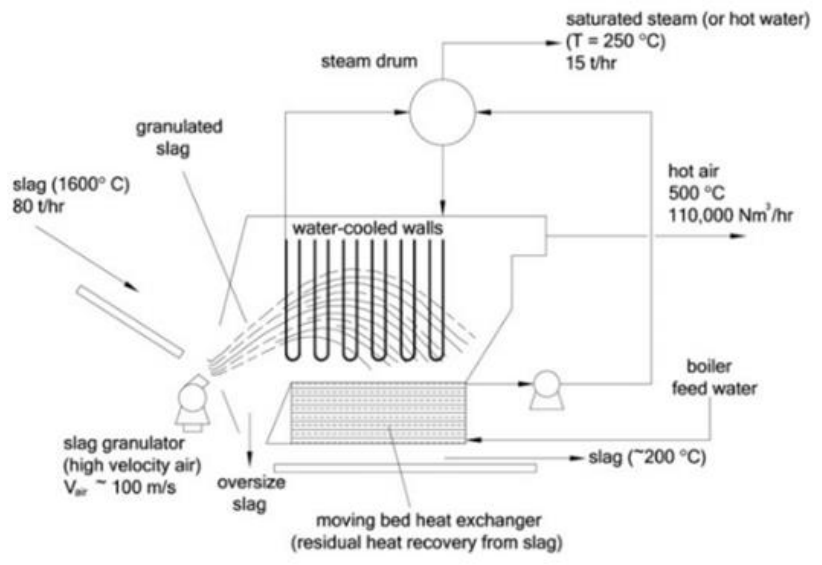

Figure 5. Schematic of molten slag heat recovery by air.

- As a result of the lower heat capacity far less than that of water, large quantities of air are required, thus result in high energy consumption of the fan and high operation cost.

- As a reason of the lower cooling speed than that of the water quenching, it is necessary to increase the size of the equipment in case the slag adhere to the surface of device. Thus the whole system covers a large area and need long payback time.

\subsection{Centrifugal granulation method}

In early 1980s, Pickering [5] and his colleagues first invented the centrifugal granulating device at Redear blast furnace of British Steel Corporation Based on the variety of the granulator, the critical component of this process, it can be divide into several different forms: Rotating Cup Atomizer (RCA) [6], Spinning Disk Atomizer (SDA), Rotating Cylinder Atomizer (RCLA) [7]. The mechanism of RCA is similar to SDA.Depend on the way to recover heat, it can also separate into physical and chemical method. From the moment it emerges, the centrifugal granulation method has attracted the eyes of the world. The process invented by Pickering is shown as follow (Fig. 6). BF slag pours into the high speed rotary cup in the heat recovery vessel from the slag supple launder. And then molten slag are thrown out to grain under the centrifugal force at the edge of the cup. Meanwhile, annular air are set at the surround of the cup for the purpose of instability wave of slag membrane so as to break up the slag. And the particle slags flow out along radial direction, slightly upward. As the slag particle flying in the air, their surface are rapidly cooled with the temperature depress $(100 \mathrm{~K} \sim 200 \mathrm{~K})$. There are cooling water pipe in the wall. After heat transfer, the slag particle rebounded to the primary fluidized bed, with a heat recovery rate of $43 \%$. Grain slag overflow to the second fluidized bed due to the swelling of primary fluidized bed and further recycling residual heat. The process obtains a heat recovery rate of $59 \%$ and average slag particles less than $2 \mathrm{~mm}$. The finally slag particles are of high glassy rate (more than 95\%) and cooled down to $250^{\circ} \mathrm{C}$

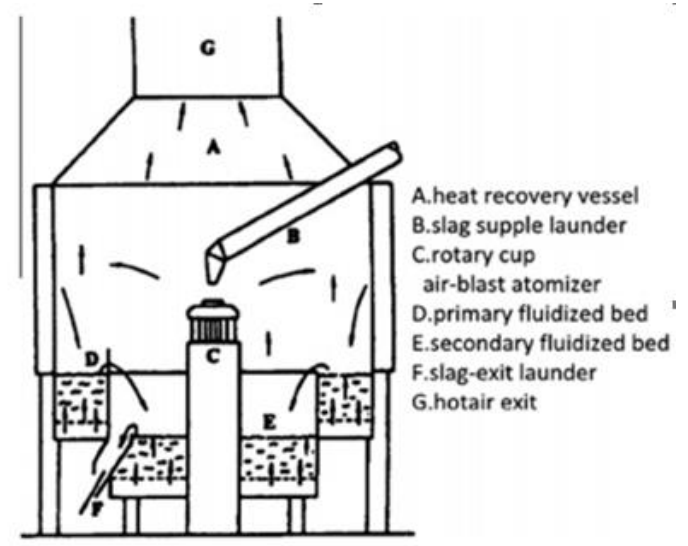

Figure 6. RCA process developed by picking.

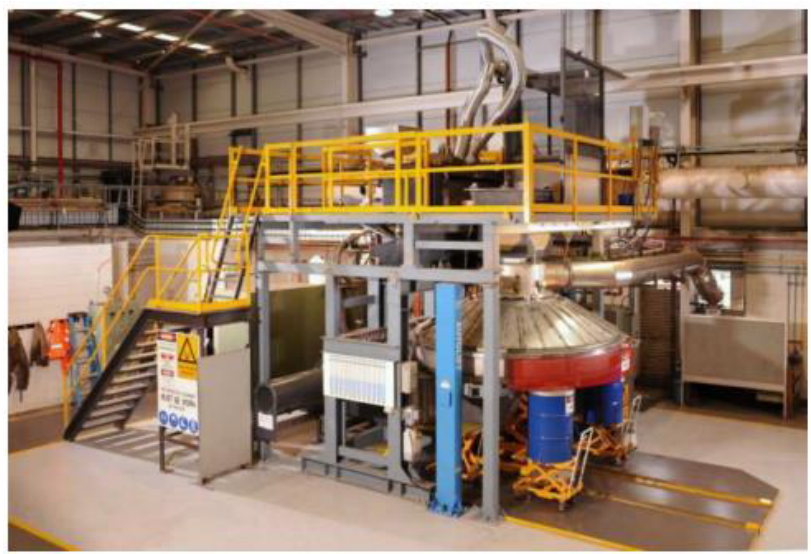

Figure 7. The semi-industrial scale ( $3 \mathrm{~m}$ in diameter) integrated heat recovery and dry granulation pilot plant at CSIRO with design throughput of 6 tonnes/hour of slag [8].

A growing number of people have focus on this method. In 2001, Mizuochi [2] focused on the Centrifugal granulation method and studied on its feasibility. In 2004, Purwanto [3] had a further research on the characteristics of glass beads frSom molten slag obtained in the RCA process, using high speed camera to observe the 
experimental process. From 2007 to 2008, Xie et al. at CSIRO forced on the researches on utilization of slag waste heat in steel plants. Furthermore, a semi-industrial scale $(3 \mathrm{~m}$ in diameter with spinning disc of up to $250 \mathrm{~mm}$ in diameter and slag tapping rates up to $100 \mathrm{~kg} / \mathrm{min}$ ) integrated dry granulation and heat recovery pilot plant at CSIRO has been built (Fig. 7). The granulated products were highly glassy ( $\sim 98 \%)$ and were found to have good cementitious properties.

\section{Conclusions}

Although there is no dry blast furnace slag processing technology to realize industrial application, the existing research has accumulated quite a lot of relevant theoretical knowledge and practical experience. From the analysis above, including rotating drum process, air blast method and centrifugal granulation method, can meet the requirements of cement material. Among them, particle size of the rotating drum method is larger, slag piece often bonding on the drum which need to clean using scratch residue board. Thus the processing capacity is limited. As to air blast method, the air as the most common heat transfer medium has a low heat transfer coefficient, causing the bigger air compressor equipment and uneconomical heat recovery process. Centrifugal granulation method is the optimum process, with smaller slag particle size (about $2 \mathrm{~mm}$ ), higher glassy phase and recovery rate. The process capacity and the cooling speed can match the blast furnace production well. So the centrifugal graining attract the most considerable attention in the world. With the promotion of Supply-side reforms in steel industry, the advance of the centrifugal granulation method in energy saving and environmental protection will be more evident. No doubt that centrifugal granulation method is the main trend and more industrial trial will be conducted both in China and abroad, once succeed, it will be widely applied.

\section{References}

1. September 2015 crude steel production. http:// apps.webofknowledge.com

2. B. Du, G. L.Ruo, R. Q. Jiang, The development of molten slag dry granulation and waste heat recovery technology, The 14th national meeting of drying technology, 3-13 (2013)

3. M. Yoshinaga, K. Fujii, T. Shigematsu, T. Nakata, Dry granulation and solidification of molten blast furnace slag, Transactions of the Iron and Steel Institute of Japan, 823-829 (1982)

4. M. Barati, S. Esfahani, T. A. Utigard: Energy recovery from high temperature slags, Energy, 54405449 (2011)

5. S. J. Pickering, N. Hay, T. F. Roylance, G. H. Thomas, New process for dry granulation and heatrecovery from molten blast-furnace slag. Ironmaking \& Steelmaking, 14-21 (1985)

6. H. Purwanto, T. Mizuochi, H. Tobo, M. Takai, T. Akiyama, Characteristics of glass beads from molten slag produced by Rotary Cup Atomizer, Materials Transactions, 3286-3290 (2004)

7. Y. Qin, X. Lv, C. Bai, P. Chen, G. Qiu, Dry granulation of molten slag using a rotating multinozzle cup Atomizer and Characterization of Slag Particles, Steel Research International, 852-862 (2013)

8. S. Jahanshahi, D. Xie, Y. Pan, et al., Dry slag granulation with integrated heat recovery; proceedings of the 1st Int Conf on Energy Efficiency and $\mathrm{CO}_{2}$ Reduction in the Steel Industry (EECR Steel 2011), F, (2011) 